\title{
Transplante Dentário Autógeno - Relato de caso clínico
}

\author{
Autogenous Dental Transplant - Clinical case report \\ Transplante dental autógeno - Reporte de caso clínico
}

\section{Resumo}

O transplante dentário autógeno dentário é caracterizado pela translocação de um elemento para outro espaço alveolar. É um procedimento considerado como um tratamento reabilitador, com bom prognóstico principalmente para pacientes jovens. Apresentando como grande vantagem o menor custo se comparada com a reabilitação com implantes e próteses fixas, além de grande aceitação pelo paciente por ser um dente próprio, sem envolver materiais "nonself". O objetivo deste trabalho é expor um relato de caso sobre transplante dentário relacionado com dentes supranumerários em região anterior de maxila. Em que foi realizada a partir de conceitos dos princípios éticos e após assinatura do Termo de Consentimento Livre e Esclarecido (TCLE) pelo responsável. Paciente melanoderma, 14 anos, apresentando elemento supranumerário na região do elemento 11. Após exames imaginológicos pôde-se notar a presença do elemento 11 impactado por palatino. Foi realizada a remoção do supranumerário e do elemento 11, sendo este transplantado para o seu alveolo ideal, sendo mantido em posição com auxílio de contenção semirrígida. No $35^{\circ}$ dia pós operatório, o paciente apresentou uma excelente recuperação e cicatrização dos tecidos periodontais. Foi retirada a esplintagem verificando-se boa estabilidade da unidade, sem mobilidade, ausência de sinais flogísticos ou alterações pulpares ao teste de vitalidade. Ao exame radiográfico percebeu-se boa adaptação da raiz, sem sinais de reabsorção. Entretanto, a literatura afirma que este acompanhamento deve ser feito por até 1 ano, objetivando analisar revascularização pulpar e necessidade posterior de endodontia. Até o presente momento, após 2 meses de follow up, o paciente não apresenta sinais de necrose pulpar e está em programação de iniciar o tratamento ortodôntico. Assim, pode-se afirmar que este é um tratamento reabilitador válido e acessível, e quando bem indicado traz bons resultados. Palavras-chave: Transplante autógeno; Dente; Odontologia; Cirurgia oral.

\begin{abstract}
Autogenous dental transplantation is characterized by the translocation of an element to another alveolar space. It is a procedure considered as a rehabilitation treatment, with a good prognosis mainly for young patients. Presenting as a great advantage the lower cost compared to the rehabilitation with implants and fixed prostheses, in addition to great acceptance by the patient for being his own tooth, without involving "nonself" materials. The objective of this work is to expose a case report on dental transplantation related to supernumerary teeth in the anterior region of the maxilla. In which it was carried out based on concepts of ethical principles and after signing the Informed Consent Form (ICF) by the person in charge. Melanoderma patient, 14 years old, presenting a supernumerary element in the region of element 11. After imaging studies, it was possible to notice the presence of element 11 impacted by palatine. The removal of the supernumerary and element 11 was performed, which was transplanted to its ideal alveolus, being maintained in position with the aid of semi-rigid containment. On the 35th postoperative day, the patient showed excellent recovery and healing of the periodontal tissues. Splinting was removed, with good stability of the unit, without mobility, absence of phlogistic signs or pulp changes to the vitality test. Radiographic examination showed good root adaptation, with no signs of resorption. However, the literature states that this follow-up must be carried out for up to 1 year, aiming to analyze pulp revascularization and the subsequent need for endodontics. To date, after 2 months of follow-up, the patient has no signs of pulp necrosis and is scheduled to start orthodontic treatment. Thus, it
\end{abstract}


can be said that this is a valid and accessible rehabilitation treatment, and when properly indicated it brings good results.

Keywords: Autogenous transplatation; Teeth; Dentistry; Oral surgery.

\begin{abstract}
Resumen
El trasplante dentario autógeno se caracteriza por la translocación de un elemento a otro espacio alveolar. Es un procedimiento considerado como tratamiento rehabilitador, con buen pronóstico principalmente para pacientes jóvenes. Presentando como una gran ventaja el menor costo frente a la rehabilitación con implantes y prótesis fijas, además de una gran aceptación por parte del paciente por ser su propio diente, sin involucrar materiales "no propios". El objetivo de este trabajo es exponer un caso clínico de trasplante dental relacionado con dientes supernumerarios en la región anterior del maxilar. En el cual se llevó a cabo en base a conceptos de principios éticos y previa firma del Formulario de Consentimiento Informado (CIF) por parte del responsable. Paciente con melanoderma, 14 años, que presenta un elemento supernumerario en la región del elemento 11. Tras los estudios de imagen, se pudo notar la presencia del elemento 11 impactado por palatino. Se realizó la remoción del elemento supernumerario y 11, el cual fue trasplantado a su alvéolo ideal, manteniéndose en posición con la ayuda de contención semirrígida. En el día 35 del postoperatorio, la paciente mostró una excelente recuperación y cicatrización de los tejidos periodontales. Se retiró ferulización, con buena estabilidad de la unidad, sin movilidad, ausencia de signos flogísticos o alteraciones pulpares a la prueba de vitalidad. El examen radiográfico mostró una buena adaptación radicular, sin signos de reabsorción. Sin embargo, la literatura indica que este seguimiento debe realizarse hasta por 1 año, con el objetivo de analizar la revascularización pulpar y la posterior necesidad de endodoncia. Hasta la fecha, después de 2 meses de seguimiento, el paciente no presenta signos de necrosis pulpar y está programado para iniciar tratamiento de ortodoncia. Así, se puede decir que se trata de un tratamiento rehabilitador válido y accesible, y cuando está debidamente indicado da buenos resultados.
\end{abstract}

Palabras clave: Trasplante autógeno; Diente; Odontología; Cirugía bucal.

\title{
1. Introdução
}

A odontologia atualmente apresenta diversas técnicas de reabilitação oral, capaz de substituir um elemento dentário perdido. Dentre elas o transplante dentário (TD) ainda perdura como uma alternativa válida, segura e menos onerosa. Consiste na remoção e transplante de um elemento dentário para um alvéolo preparado cirurgicamente. Logo, o TD é feito objetivando a substituição de dentes perdidos, principalmente em pacientes jovens e de menor renda, visto que é um tratamento economicamente favorável se comparado à instalação de implantes (Zakershahrak et al. 2017). Além disso, o TD pode atuar como coadjuvante no tratamento ortodôntico, objetivando induzir a movimentação dentária induzida (de Barros et al., 2012).

Os relatos dos primeiros transplantes dentários foram em 1050 a.C no Egito Antigo, em que os escravos eram obrigados a dar seus dentes aos faraós, não obstante, o transplante de um dente de outro individuo não era exitoso em virtude da falta de histocompatibilidade. Todavia, a técnica foi documentada pela primeira vez em meados de 1950 por Hale, sendo a técnica e os principios atualmente aplicados (Modaress, 1977).

Vantagens como melhora na estética, mastigação, manutenção e integridade do periodonto, preservação do volume e integridade óssea são as principais encontradas na literatura. Mas vale ressaltar que o sucesso está atrelado a adequada indicação para este procedimento, sabe-se que elementos dentais com o ápice ainda aberto possuem maiores chances de sucesso e manutenção da vitalidade pulpar. Não obstante, em elementos com a raiz totalmente formada é comumente necessário o tratamento endodôntico posterior (Nagori et al. 2016; Zakershahrak et al. 2017).

Em relação as suas desvantagens, pode ocorrer anquilose ou reabsorção radicular e a necessidade de um dente doador em condições favoráveis. Além de que o paciente deve ser colaborativo e possuir uma boa higiene bucal. Suas principais indicações são em casos de dentes impactados, agenesias, perda traumática e patologias que levaram a perda precoce do elemento dental. O sucesso do transplante é dependente de fatores associados aos sítios doadores e receptores e da habilidade profissional em preservar o meio (Mikami et al. 2014).

A perda precoce do elemento dentário pode gerar alterações no sistema estomatognático e ainda prejuízos na estética facial. O transplante proporciona a reabilitação imediata do caso, evitando sequelas e perdas teciduais futuras. Assim sendo, o 
objetivo deste trabalho é expor um relato de caso sobre transplante dentário relacionado com dentes supranumerários em região anterior de maxila.

\section{Metodologia}

O presente estudo remete-se à um relato de caso clínico cirúrgico, caracterizando-se em um estudo descritivo através da busca em bases de dados Pubmed, Scielo (Scientific Eletronic Library On-line) e Google Acadêmico que consiste em uma pesquisa qualitativa. Em que foi realizada a partir de conceitos dos princípios éticos respeitando todos os princípios éticos da Declaração de Helsinque e após assinatura do Termo de Consentimento Livre e Esclarecido (TCLE) pelo responsável. As palavras-chaves utilizadas foram: Transplante Autólogo (Autogenous Transplantation); Dente (Teeth); Odontologia (Dentistry); Cirurgia Oral (Oral Surgery).

\section{Caso clínico}

Paciente S. R. S. J, gênero masculino, melanoderma, 14 anos, compareceu ao serviço particular de cirurgia bucomaxilofacial para a realização do tratamento de extração das unidades dentárias supranumerárias localizadas na região de incisivos, palatinamente. Ao exame físico percebeu-se a presença de uma unidade supranumerária localizada na região da unidade 11, com a coroa semi-erupcionada. Enquanto na radiografia panorâmica foi observada a presença de 3 unidades supranumerárias, e da unidade 11, situada próxima à fossa nasal (Figura 1). Optou-se por realizar a remoção das unidades supranumerárias e do elemento 11 e por fim realizar o transplante da unidade onze para região do seu alvéolo correspondente.

Figura 1 - Radiografia panorâmica pré-operatória evidenciando os elementos supranumerários na região do dente 11.

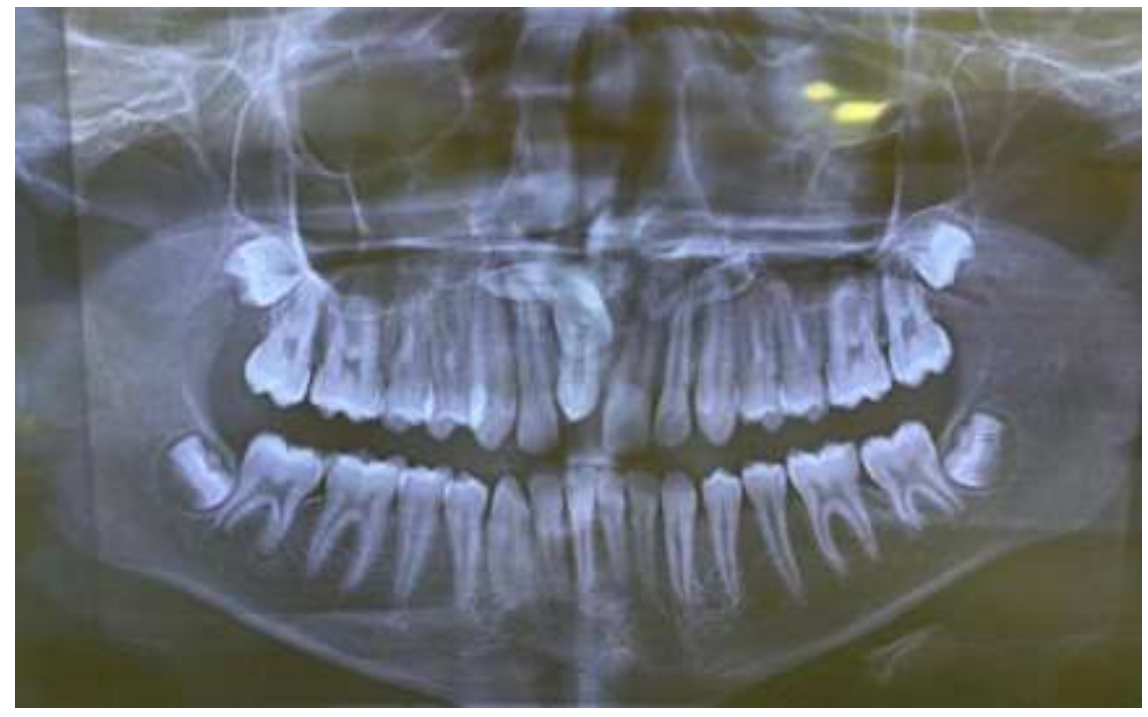

Fonte: Autores (2021).

Assim então, a partir da análise da radiografia panorâmica (Figura 1) entende-se que o elemento visível em cavidade bucal seria um supranumerário enquanto o elemento 11 estava retido intra-ósseo. Todo o procedimento foi realizado com o paciente levemente sedado, fazendo uso do midazolam $7,5 \mathrm{mg}$, associado ao clonidin via nasal, para um maior conforto do próprio durante o procedimento. Em seguida prosseguiu-se com o bloqueio do nervo infraorbitário e bloqueio do nervo nasopalatino, além da técnica de anestesia infiltrativa. Realizada uma incisão relaxante, desde a distal do primeiro pré-molar superior direito (14) à distal do incisivo central superior esquerdo (21), realizado descolamento subperiosteal vestibular e 
palatino, osteotomias localizadas na região anterior da maxila, próximo ao nível das unidades 11 e 12 e remoção das unidades supranumerárias e da unidade 11 (Figura 2).

Figura 2 - Osteotomias realizadas na região anterior da maxila para remoção das unidades supranumerárias e da unidade 11.

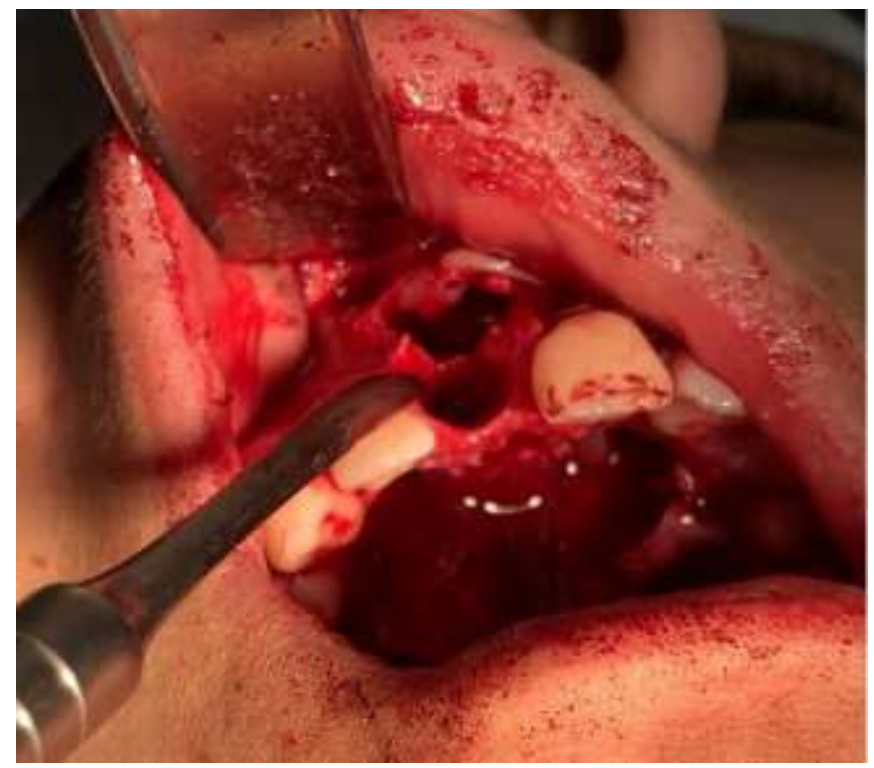

Fonte: Autores (2021).

Colocou-se a unidade $11 \mathrm{em}$ uma cuba com soro fisiológico 0,9\% (Figura 3). Na etapa seguinte foi feito o reparo e adaptação do alvéolo para receber a unidade a ser transplantada, em seguida realizada a implantação do elemento 11 no álveolo dentário fresco. Para reconstrução dos defeitos ósseas pós exodontia realizou-se aplicação de enxerto ósseo bovino e recobrimento com membrana de colágeno. Síntese realizada com o fio nylon 4.0 e por fim a esplintagem da unidade utilizando fio ortodôntico e resina composta, aproximando a unidade 11 às unidades 12 e 21 (Figura 4).

Figura 3 - Elemento submerso na solução de soro fisiológico 0,9\% estéril.

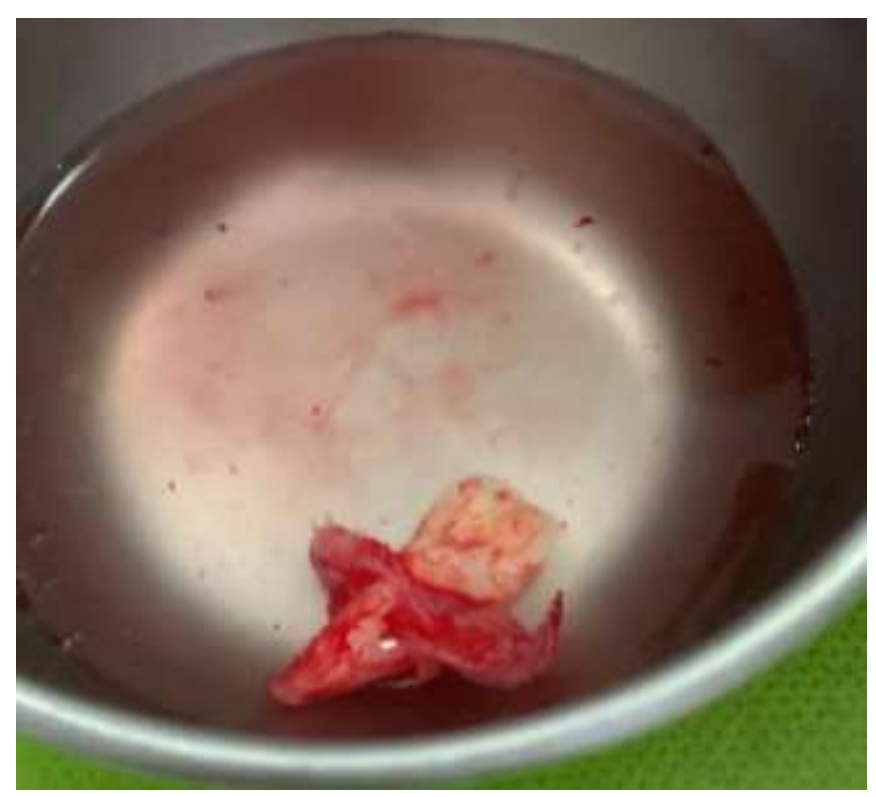

Fonte: Autores (2021). 
Figura 4 - Elemento 11 após esplintagem.

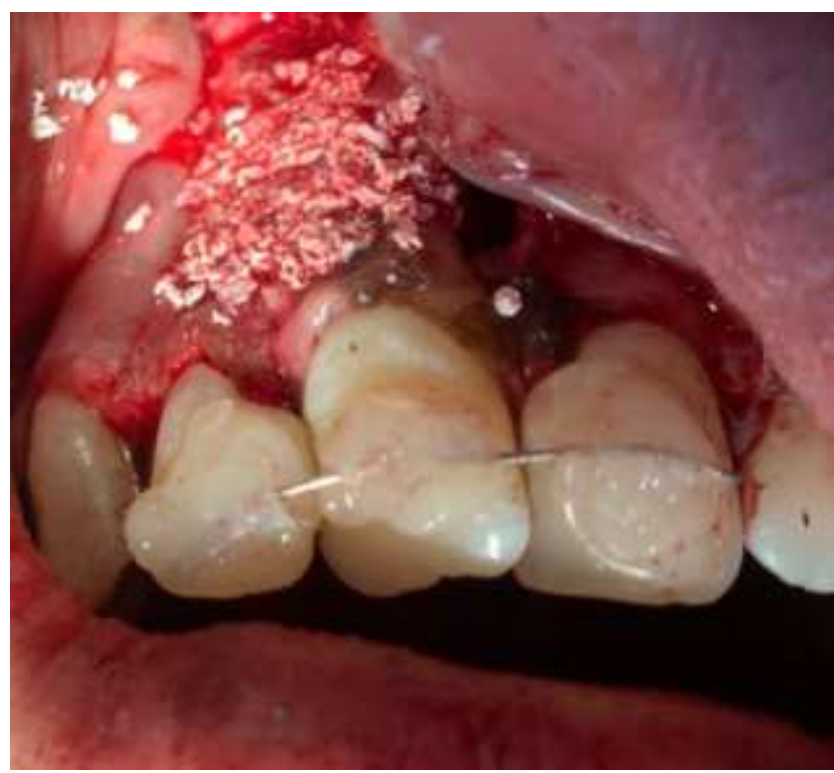

Fonte: Autores (2021).

Após o procedimento, o paciente foi medicado com Lânico (01 comprimido de 12/12h, durante 10 dias), Meticorten 20mg (01 comprimido de 12/12h, durante 05 dias), Cod Par (01 comprimido de 06/06h, durante 05 dias), além de bochechos com digluconato de clorexidina $0,12 \%$ (de 06/06h, durante 14 dias). Orientação de dieta líquida/pastosa durante cerca de 45 dias, visto que seria o tempo necessário para que a unidade dentária transplantada se estabilizasse no alvéolo, respeitando todo o processo da regeneração óssea.

Após 01 semana, o paciente retornou ao consultório para a remoção da sutura e avaliação. Notou-se boa aderência da unidade em seu alvéolo e o tecido gengival com excelente recuperação, remodelação óssea e estado clínico (Figuras 5A, 5B e $6)$.

Figura 5A e B - Radiografia panorâmica e periapical após 7 dias do procedimento.
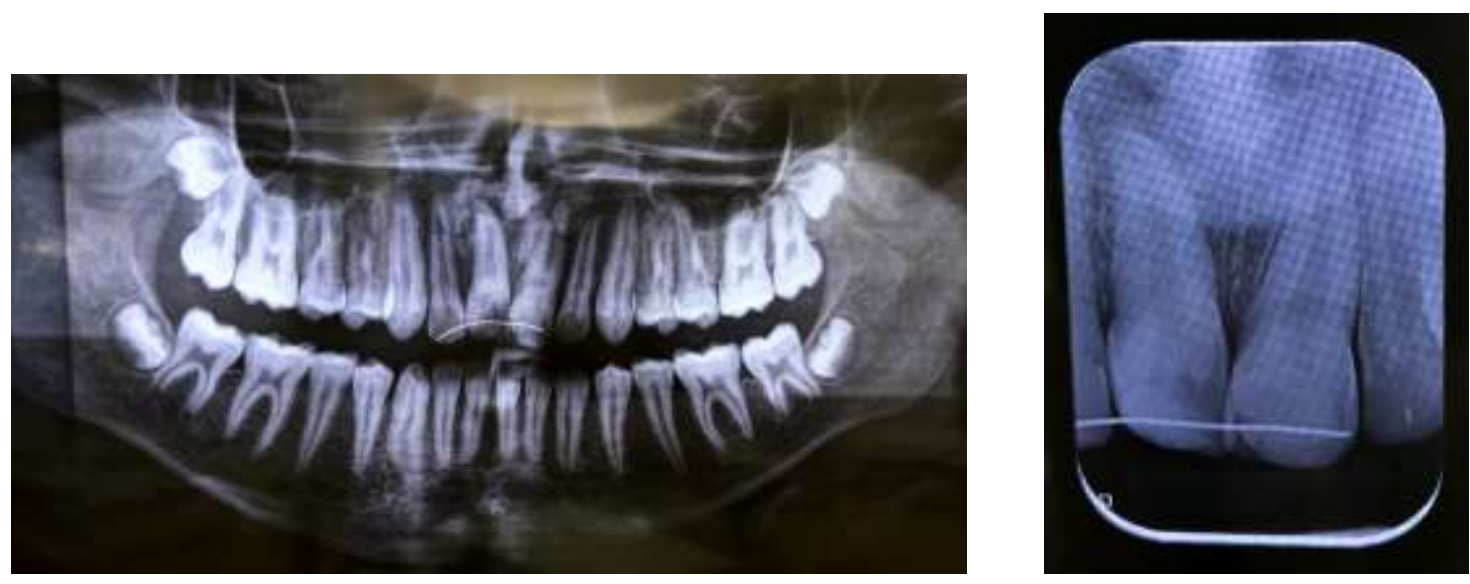

Fonte: Autores (2021).

A partir do exame radiográfico, notou-se boa adaptação do elemento, sem sinais de reabsorção. 
Research, Society and Development, v. 10, n. 5, e53810515262, 2021

(CC BY 4.0) | ISSN 2525-3409 | DOI: http://dx.doi.org/10.33448/rsd-v10i5.15262

Figura 6 - Aspecto intra-oral após 7 dias do procedimento.

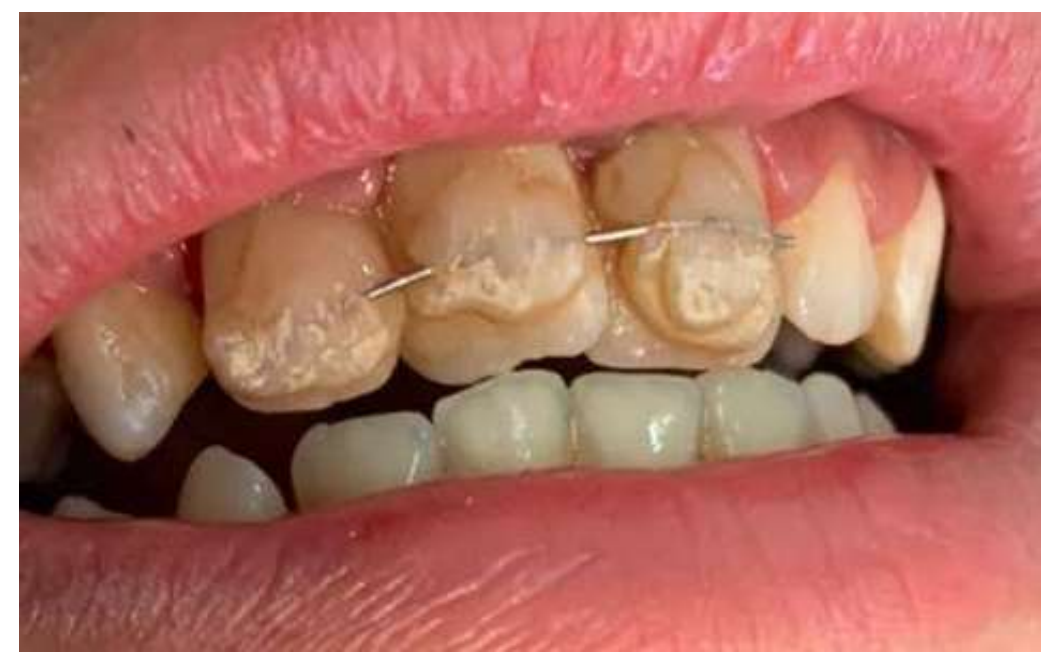

Fonte: Autores (2021).

Passados 35 dias do procedimento (Figura 7), o paciente segue em franca recuperação. Foi retirada a esplintagem verificando-se boa estabilidade da unidade, sem mobilidade, ausência de sinais flogísticos ou alterações pulpares.

Figura 7 - Aspecto intraoral após 35 dias do procedimento durante o teste de mobilidade.

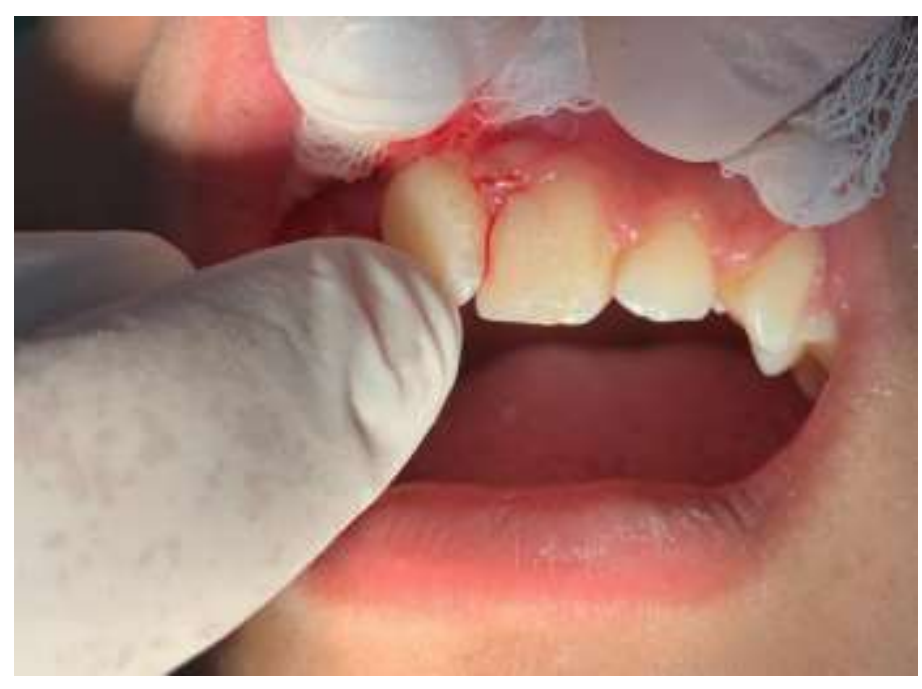

Fonte: Autores (2021).

Após 2 meses (Figura 8), o paciente segue com um excelente prognóstico. Ao ser encaminhado ao endodontista, passou por testes semiotécnicos, sem alterações. Ao exame radiográfico percebeu-se boa adaptação da raiz, notou-se leve remodelação apical em um nível já previsto (Figura 9). 
Figura 8 - Aspecto intra-oral após 2 meses.

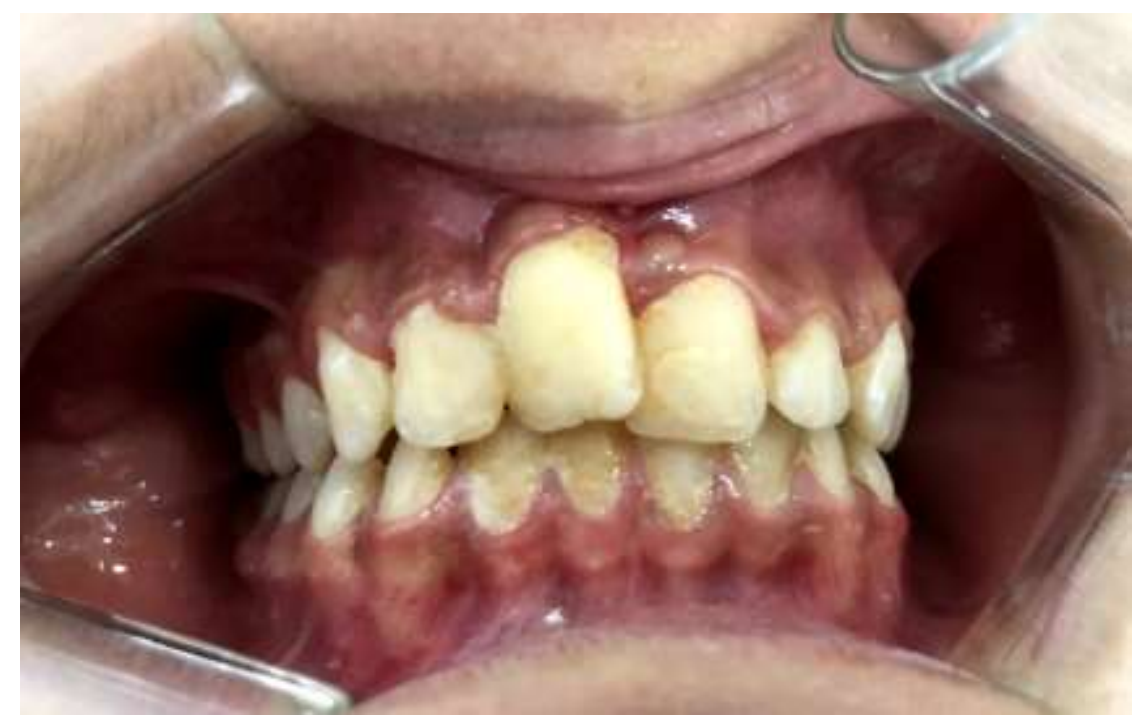

Fonte: Autores (2021).

Nota-se a adaptação do elemento e má oclusão dentária, este então foi encaminhado também para a ortodontia. Assim, a partir da radiografia periapical (Figura 9) pode-se notar um progresso na neoformação óssea na região onde estavam alojados os elementos supranumerários e o elemento permanente.

Figura 9: Radiografia periapical após 2 meses do procedimento.

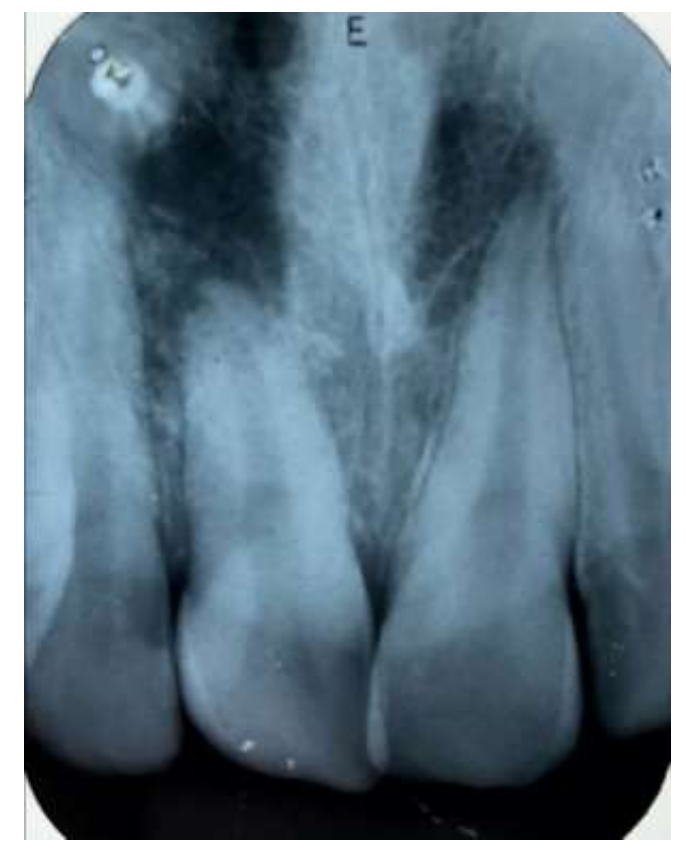

Fonte: Autores (2021).

Logo, fica evidente que este tratamento exige uma equipe multidisciplinar, envolvendo a cirurgia buco-maxilo-facial, a endodontia e a ortodontia.

\section{Discussão}


O autotransplante dental é caracterizado pela transposição dentária no próprio paciente, este procedimento foi citado pela primeira vez na literatura em meados de 1900 por Wideman que apresentou um caso de transplante de caninos impactados (Giancristófaro et al. 2017). Esta técnica representa uma opção de tratamento viável frente à casos de perda precoce do elemento dentário, principalmente em pacientes jovens ou ainda, nos casos de impacção dentária como no caso apresentado. Ao se comparar com implante dentário, o TD permite a preservação do osso alveolar e da papila interdental e a movimentação dentária por forças ortodônticas ou fisiológica. Dentre suas principais vantagens consiste na sua indicação para pacientes em fase de crescimento e o menor custo, se comparado a outras formas de reabilitação oral (Rohof et al. 2018).

Segundo Martin, Nathwani e Bunyan (2018) existem complicações que podem surgir no pós-operatório, tais como necrose pulpar, reabsorção radicular, doença periodontal e anquilose. Não obstante, no caso apresentado o paciente teve uma evolução satisfatória no pós-operatório e foi notado vitalidade pulpar no elemento transplantado. Existem ainda, propriedades ideais que os dentes doadores e local receptor devem possuir, tais como: o dente doador deve ser hígido, deve ter uma posição não funcional na oclusão, tamanho da coroa apropriado para o local receptor, extração minimamente traumática e pacientes com idade menor que 40 anos. Além de que, a literatura preconiza a indicação para pacientes sem doenças sistêmicas e com boas condições de higiene oral (da Silva et al., 2020; Duarte et al., 2017; Ribeiro, Bastos, \& Alberconi, 2015).

Quanto às características radiográficas, as indicações são para elementos preferencialmente com rizogênese incompleta ou com metade à $2 / 3$ da raiz formada. Em relação ao local receptor, este deve estar livre de inflamação, tamanho mesio-distal adequado, proximidade com estruturas nobres e que possa receber uma boa adaptação do elemento doador (Martin, Nathwani, and Bunyan 2018). O presente relato esteve de acordo com as indicações disponíveis na literatura, visto que era um paciente jovem com o elemento 11 impactado e possibilidade de transplante devido as características do elemento doador e local receptor. Entretanto, mesmo o elemento doador do caso relatado já houvera finalizado a rizogênese, este obteve uma boa adaptação e histocompatibilidade no local receptor.

Não há ainda um padrão na literatura a fim de determinar o sucesso desta abordagem reabilitadora. Contudo, a maioria dos autores possuem parâmetros clínicos e radiográficos em comum, como profundidade de sondagem, som da percussão e sensibilidade dentária, sinais de reabsorção radicular, obliteração pulpar e anquilose (Akhlef, Schwartz, Andreasen and Jensen, 2020). No caso proposto o paciente apresentou profundidade de sondagem de $3 \mathrm{~mm}$ e sem sinais de patologias ou alterações associadas. Alguns autores ainda apontam o planejamento multidisciplinar, visto que comumente esses elementos necessitarão de tratamento endodôntico posteriormente (Candeiro et al. 2015; Giancristófaro et al. 2017), mas o dente transplantado no caso apresentado obteve vitalidade pulpar de acordo com os exames periódicos de controle, não necessitando, logo, do tratamento endodôntico.

Existem ainda duas técnicas de implantação, a técnica imediata ou o transplante tardio. A maioria dos autores preconizam a técnica imediata de forma concomitante a exodontia do elemento, como realizado no caso clínico. O período de tempo fora do alvéolo é um fator essencial no prognóstico TD. Assim, o elemento dental é mantido em solução com soro fisiológico 0,9\% até o momento de adequação no alvéolo (Mikami et al. 2014; Modaress 1977), no caso demonstrado, o elemento 11 permaneceu imerso somente até a adequação alveolar para receber o elemento dentário, feito em uma mesma sessão.

Após a instalação do elemento dentário, há uma divergência na literatura relacionado ao tipo e o período de contenção do elemento transplantado. Alguns autores sugerem que a esplintagem da unidade deve permanecer de 3 a 4 meses (Almeida et al., 2020) Já no caso apresentado, após 35 dias notou-se boa estabilidade do elemento transplantado, sem mobilidade, e com isso optou-se por retirar a contenção que o ligava às unidades adjacentes.

Segundo Kafourou et al. (2017), o transplante dentário em crianças e adolescentes apresenta uma taxa de sucesso geral de 87,6\%. Dentro desde índice, 94,4\% apresentou vitalidade pulpar. Em alguns casos, opta-se pelo tratamento 
endodôntico imediato (Marzola 1997; Nogueira 2004), antecipando este procedimento que possivelmente será realizado no futuro. Porém, no caso apresentado o elemento transplantado permanece saudável.

O transplante dentário se apresenta como uma alternativa de tratamento reabilitador (Rebouças et al. 2015). Apesar do sucesso dos implantes dentários, que vem tornando este procedimento cada vez mais raro, o mesmo se torna uma alternativa viável, visto que possui bons resultados e apresenta baixo custo, se tornando acessível à pacientes de baixa renda (Duarte et al., 2017).

O autotransplante dental apresenta inúmeros benefícios quando comparados a outros tipos de tratamento, podendo ser aplicado até mesmo em casos de traumatismo dentário (Santinoni et al., 2021). De acordo com Reich (2008), o dente transplantado pode regenerar osso, ao contrário dos implantes dentários, que geralmente necessitam de enxerto ósseo para devolver todas as necessidades estéticas e funcionais ao paciente. Além disso, este potencial regenerador dentário vem sendo analisado com a finalidade de futuramente desenvolver dentes clonados em laboratório, com o auxilio de células mesenquimais da medula óssea para a semeadura da regeneração dentária (Young Li Z; Chen L; Liu L, 2007).

\section{Conclusão}

Considerando que os transplantes dentários se tratam uma forma de tratamento viável e de baixo custo, acaba se tornando uma boa alternativa, principalmente em pacientes jovens, onde a incidência de sucesso no procedimento é consideravelmente maior.

Nos tempos de hoje, onde os implantes dentários se encontram em alta, procedimentos como este não devem ser descartados, visto que em situações onde se encontram condições favoráveis aliadas à limitação socioeconômica do paciente, o transplante dentário pode ser uma excelente alternativa de tratamento por ser um procedimento conservador, com excelentes resultados, gerando menos trauma ao paciente.

O transplante dentário é um tratamento ainda pouco estudado. De acordo com a literatura, ainda não existe um padrão das etapas do procedimento a serem seguidas, o que abre um leque de possibilidades a serem discutidas. Cabe a cada profissional verificar a melhor alternativa a ser escolhida, seguindo todos os protocolos e visando a saúde e o bem estar de seu paciente.

\section{Referências}

Akhlef, Y., Schwartz, O., Andreasen, J. O., \& Jensen, S. S. (2017). Autotransplantation of teeth to the anterior maxilla: A systematic review of survival and success, aesthetic presentation and patient-reported outcome. Dental Traumatology, 34(1), $20-27$.

Almeida, G. M., Cavalcanti, R. B. d. M. S., de Souza Medeiros, G., de Araújo Almeida, M. D., Castro, R. M., \& Andrade, M. A. (2020). Aproveitamento de dentes inclusos: relato de casos. Development. 9(7), e653974585-e653974585.

Candeiro, G. T., Alencar-Júnior, E. A., Scarparo, H. C., Furtado-Júnior, J. H., Gavini, G., \& Caldeira, C. L. (2015). Eight-year follow-up of autogenous tooth transplantation involving multidisciplinary treatment. Journal of oral science, 57(3), 273-276.

da Silva, R. M., Rocha, J. F., de Medeiros, L. A. D. M., Maia, L. S., Goes, V. N., \& de Oliveira, O. L. (2020). Conhecimento de estudantes de Odontologia sobre autotransplante dentário. Development, 9(7), e641974632-e641974632.

de Barros, M. G. L., Roldi, A., Bortolotti, R., Barroso, J. M., Ribeiro, F. C., de Souza Pereira, R., \& Intra, J. B. (2012). Movimentação dentária induzida em dentes autotransplantados. Revista Brasileira de Pesquisa em Saúde/Brazilian Journal of Health Research, 14(3),38-44.

Duarte, É. E. N., Macedo, I. R. R., de Carvalho, W. R. S., do Couto Oliveira, H., Cristino, M. R., \& Neto, N. C. J. R. D. A. (2017). Autotransplante dentáriouma alternativa viável para a reabilitação dentária. Revista Digital APO, 1(1), 29-34.

Giancristófaro, M., Júnior, W. P., Júnior, N. V. R., Júnior, H. M., \& de Oliveira, C. (2017). Transplante dental: revisão da literatura e relato de caso. Revista de Odontologia da Universidade Cidade de São Paulo, 21(1), 74-78.

Kafourou, V., Tong, H. J., Day, P., Houghton, N., Spencer, R. J., \& Duggal, M. (2017). Outcomes and prognostic factors that influence the success of tooth autotransplantation in children and adolescents. Dental Traumatology, 33(5), 393-399.

Martin, K., Nathwani, S., \& Bunyan, R. (2018). Autotransplantation of teeth: an evidence-based approach. British dental journal, $224(11), 861-864$. 
Research, Society and Development, v. 10, n. 5, e53810515262, 2021

(CC BY 4.0) | ISSN 2525-3409 | DOI: http://dx.doi.org/10.33448/rsd-v10i5.15262

Marzola, C. (1997). Transplantes e reimplantes. (2a ed.), Pancast; 1997. 382p.

Mikami, J. R., Laureano Filho, J. R., Nogueira, P. T. B. de C., Brasil Júnior, O., Silva Júnior, E. Z., \& Nogueira Filho, L. L. T. Transplante Dental Autógeno Relato de caso. Rev Cir e Traumatol Buco-maxilo-facial, 14(4),51-8.

Modaress R (1977). Autogenous tooth transplantation. J Dent Sch Natl Univ Iran, 9(1), 39-46.

Nagori SA, Jose A, Arora A, Gagnani S, Kholakiya Y, Agarwal B, et al (2016). Misconceptions Regarding Autogenous Tooth Transp lantations: A Survey. $J$ Maxillofac Oral Surg, 15(2), 173-8.

Nogueira A. (2004). Abordagem contemporânea dos dentes inclusos - Do Diagnóstico ao Tratamento Cirúrgico e Ortodôntico. Santos.

Rebouças, D. S., Cerqueira, L. S., Andrade, E. L., Santos, H. L., Zerbinati, L. P. S., \& Assis, A. F. (2015). Autotransplante dentário: uma opção reabilitadora e viável ao sus. Revista Bahiana de Odontologia. 6(1)47-51.

Reich, P. P. (2008). Autogenous Transplantation of Maxillary and Mandibular Molars. Journal of Oral and Maxillofacial Surgery, 66(11), $2314-2317$.

Ribeiro, T. T. d. C., Bastos, R. T. d. R. M., \& Alberconi, T. F. J. O. S., (2015). Tratamento ortodôntico com autotransplante dentário em paciente com fissura palatina. Orthod. sci. pract, $10(2), 89-95$.

Rohof, E., Kerdijk, W., Jansma, J., Livas, C., \& Ren, Y. (2018). Autotransplantation of teeth with incomplete root formation: a systematic review and metaanalysis. Clinical oral investigations, 22(4), 1613-1624.

Santinoni, C. dos S., Gonçalves, G. S. Y., Santos, B. A., João, S. A. R. O., Marsicano, J. A., Prado, R. L., \& Mori, G. G. (2021). Dental avulsion management by emergency professionals and efficacy of education. Research, Society and Development, 10(4), e42210414393.

Yong Li, Z., Chen, L., \& Liu, L. (2007). Odontogenic potential of bone marrow mesenchymal stem cells. J Oral Maxillofac Surg. 65 (02), 494.

Zakershahrak, M., Moshari, A., Vatanpour, M., Khalilak, Z., \& Ara, A. J. (2017). Autogenous transplantation for replacing a hopeless tooth. Iranian endodontic journal, 12(1), 124. 